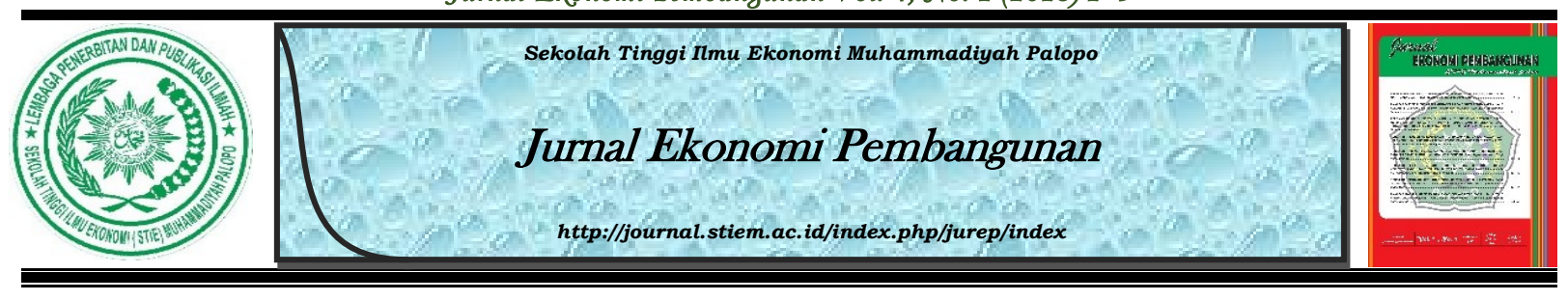

\title{
Analisis Penerapan Electronic Data Processing (EDP) System dalam Pengolahan Data Penjualan dan Penerimaan Kas Pada PT Hadji Kalla Cabang Parepare
}

\author{
Arfianty
}

\section{Universitas Muhammadiyah Parepare}

\section{INFO NASKAH}

Diserahkan

9 September 2018

Diterima

13 September 2018

Diterima dalam revisi

10 Oktober 2018

Diterima dan disetujui

29 Desember 2018

Kata Kunci:

Eletronic data processing

Penerimaan kas

Pengolahan data

Penjualan

\begin{abstract}
ABSTRAK
Tujuan penelitian ini adalah untuk mengetahui mekanisme yang digunakan PT Hadji Kalla Cabang Parepare dalam pengolahan data penjualan dan penerimaan kas; dan mengetahui apakah penerapan electronic data processing (EDP) System pada PT Hadji Kalla Cabang Parepare telah mendukung pencapaian informasi akuntansi yang akurat. Adapun sumber data yang digunakan dalam penelitian ini meliputi place, paper, dan person. Teknik analisis data yang digunakan dalam penelitian ini adalah teknik analisis deskriptif kualitatif, yaitu metode analisis data yang menggambarkan dan menginterpretasikan serta membandingkan data-data penelitian yang diperoleh dari perusahaan dengan literaturliteratur yang ada untuk dianalisa sehingga memberikan keterangan bagi pemecahan masalah yang dihadapi. Setelah melalui proses pengumpulan, penyusunan, dan analisis data, maka diperoleh hasil bahwa dalam penerapan electronic data processing (EDP) system, PT Hadji Kalla Cabang Parepare menggunakan mekanisme pengolahan data secara langsung (real time processing) yang dapat dibuktikan melalui tabel indikator real time processing yang telah disesuaikan berdasarkan hasil dari wawancara dan observasi,dan juga diperoleh hasil bahwa penerapan electronic data processing (EDP) telah mendukung pencapaian informasi akuntansi yang akurat berdasarkan komponen-komponen electronic data processing (EDP) system pada PT Hadji Kalla Cabang Parepare telah memadai.
\end{abstract}

\section{Pendahuluan}

Salah satu dari beberapa penunjang perusahaan untuk mampu menjadi perusahaan yang maju dan unggul adalah sistem teknologi yang digunakannya. Begitupun dengan proses pengolahan data dengan menerapkan sistem electronic data processing (EDP) yang bertujuan agar setiap data transaksi dapat diolah dengan cepat untuk menghasilkan informasi yang akurat, relevan, lengkap dan tepat waktu. Menurut Jogiyanto (2008:36) “informasi 
(information) adalah data yang diolah menjadi bentuk yang berguna bagi para pemakainya”.

Pengolahan data berbasis elektronik juga membutuhkan keahlian khusus. Sehingga untuk melakukan pengolahan data diperlukan orang yang ahli dalam mengoperasikan aplikasi pengolah data elektronik tersebut. Jika pengolahan data berbasis elektronik tersebut dilakukan oleh orang yang tidak ahli, maka itu bisa berdampak buruk pada perusahaan, seperti terjadinya kesalahan olah data yang berakibat pada kurang tepatnya informasi keuangan yang dihasilkan, sehingga antara kualitas teknologi dan kualitas sumber daya manusia yang baik perlu untuk dipadukan.

Teknologi sangat dibutuhkan perusahaan dalam menjalankan aktivitas operasionalnya, termasuk pemanfaatan teknologi dalam pengolahan data karena dengan pemanfaatan teknologi maka perusahaan dapat menciptakan efektifitas dan efisiensi dalam opersionalnya sehari-hari. Begitupun dengan PT Hadji Kalla Cabang Parepare yang membutuhkan manfaat dari teknologi untuk memudahkan dalam pengolahan data penjualan dan penerimaan kas. Perusahaan dalam pengambilan keputusan, tentunya memerlukan informasi akuntansi yang akurat dan memadai.

Penelitian ini bertujuan untuk mengetahui penerapan electronic data processing (EDP) system, mekanisme apa yang digunakan oleh pihak PT Hadji Kalla Cabang Parepare dalam pengolahan data penjualan dan penerimaan kas. Penelitian ini juga bertujuan untuk mengetahui apakah penerapan sistem electronic data processing (EDP) telah mendukung pencapaian informasi akuntansi yang akurat. Penelitian yang dilakukan pada dasarnya diharapkan dapat memberi manfaat bagi pihak-pihak terkait, khususnya pengkajian terhadap pengolahan data berbasis elektronik atau electronic data processing (EDP) dan sebagai sumbangsi saran kepada semua pihak yang terkait, khususnya bagi pihak PT Hadji Kalla Cabang Parepare sebagai pengguna sistem pengolah data berbasis elektronik.

\section{Metode Penelitian}

\subsection{Pendekatan Penelitian}

Penelitian ini bertujuan untuk mengetahui penerapan electronic data processing (EDP) system, mekanisme apa yang digunakan oleh pihak PT Hadji Kalla Cabang. Penelitian ini dilakukan dengan pendekatan kuantitatif yang menggambarkan dan menginterpretasikan serta membandingkan data-data penelitian yang diperoleh dari perusahaan dengan literatur-literatur 
yang ada untuk dianalisa sehingga memberikan keterangan bagi pemecahan masalah yang dihadapi.

\subsection{Jenis dan Sumber Data}

Jenis data yang digunakan dalam penelitian ini terdiri dari dua jenis data, yaitu data kualitatif dan data kuantitatif. Data kualitatif yaitu data yang berbentuk informasi dan merupakan hasil interpretasi dari hasil wawancara dan observasi terkait dengan penerapan sistem electronic data processing (EDP) yang dilakukan secara langsung oleh peneliti pada pihak PT Hadji Kalla Cabang Parepare. Data Kuantitatif yaitu data yang diperoleh dari perusahaan berupa data yang dapat dihitung atau berupa angka yang diperoleh dari perusahaan, seperti jumlah unit komputer yang digunakan dalam pemrosesan data.

Adapun sumber data yang yang digunakan dalam penelitian ini dapat dibedakan dalam tiga jenis. Pertama, person, yaitu data yang diperoleh dari pihak manajer perusahaan dengan cara wawancara langsung (interview). Kedua paper, yaitu data yang diperoleh melalui berbagai literatur seperti buku, skripsi, junal ilmiah akuntansi, atau artikel lainnya yang ada kaitannya dengan variabel penelitian. Ketiga place, yaitu data yang diperoleh dari lokasi penelitian. Lokasi yang dimaksud adalah perusahaan tempat penulis melakukan penelitian, yaitu PT Hadji Kalla Cabang Parepare.

\subsection{Variabel Penelitian}

Variabel penelitian ini adalah sistem, data, informasi, dan electronic data processing. Sistem dalam penelitian ini merupakan gabungan dari berbagai unsur yang saling bekerja sama untuk mencapai tujuan. Data dalam penelitian ini adalah sebuah fakta yang dikumpulkan, disimpan, dan diproses dengan menggunakan teknologi untuk menghasilkan informasi. Informasi dalam penelitian ini adalah data yang diolah kemudian menjadi bentuk yang lebih berguna dan lebih berarti bagi penerimanya, menggambarkan suatu kejadian, dan kesatuan nyata, serta digunakan untuk pengambilan keputusan. Electronic Data Processing (EDP) dalam penelitian ini adalah pemanfaatan teknologi komputer untuk melakukan pengolahan data yang berorientasi pada transaksi dalam suatu organisasi. 


\subsection{Teknik Pengumpulan Data}

Teknik pengumpulan data yang digunakan dalam penelitian ini adalah dengan observasi, wawancara dan dokumentasi. Observasi dalam penelitiaj ini dilakukan dengan pengumpulan data melalui pengamatan langsung yang dilakukan di PT Hadji Kalla Cabang Parepare. Kemuadian wawancara dilakukan dengan melakukan tanya jawab langsung (interview) dengan pihak perusahaan terkait dengan variabel penelitian. Adapun dokumentasi dalam penelitian ini dilakukan dengan pengumpulan data melalui pencatatan bukti-bukti atau dokumen-dokumen yang relevan dengan masalah penelitian.

Tabel 1. Indikator Real Time Processing

\begin{tabular}{|c|c|c|c|}
\hline No & Indikator Real Time Processing & Hasil Analisis & Instrumen \\
\hline 1 & $\begin{array}{l}\text { Pengolahan data dilakukan dengan } \\
\text { segera atau secara langsung saat } \\
\text { selesainya transaksi }\end{array}$ & - & $\begin{array}{c}\text { Wawancara dan } \\
\text { observasi }\end{array}$ \\
\hline 2 & $\begin{array}{l}\text { Data yang diolah merupakan data } \\
\text { transaksi yang berintensitas tinggi } \\
\text { dan sifatnya rutin }\end{array}$ & - & $\begin{array}{c}\text { Wawancara dan } \\
\text { observasi }\end{array}$ \\
\hline 3 & $\begin{array}{l}\text { Dapat menampilkan informasi yang } \\
\text { dibutuhkan kapan saja sesuai } \\
\text { keperluan }\end{array}$ & - & $\begin{array}{c}\text { Wawancara dan } \\
\text { observasi }\end{array}$ \\
\hline
\end{tabular}

Tabel 2. Komponen Electronic Data Processing

\begin{tabular}{|c|l|c|c|}
\hline No & Komponen Electronic Data Processing & Hasil Analisis & Instrumen \\
\hline 1 & $\begin{array}{l}\text { Perangkat Keras (hardware) yang } \\
\text { memadai }\end{array}$ & - & $\begin{array}{c}\text { Wawancara dan } \\
\text { observasi }\end{array}$ \\
\hline 2 & $\begin{array}{l}\text { Perangkat Lunak (software) yang } \\
\text { memadai }\end{array}$ & - & $\begin{array}{c}\text { Wawancara dan } \\
\text { observasi }\end{array}$ \\
\hline 3 & Pengguna (brainware) yang memadai & - & $\begin{array}{c}\text { Wawancara dan } \\
\text { observasi }\end{array}$ \\
\hline 4 & Prosedur yang memadai & - & $\begin{array}{c}\text { Wawancara dan } \\
\text { observasi }\end{array}$ \\
\hline 5 & Jaringan Komputer yang memadai & - & $\begin{array}{c}\text { Wawancara dan } \\
\text { observasi }\end{array}$ \\
\hline
\end{tabular}




\section{Hasil dan Pembahasan}

\subsection{Hasil}

PT Hadji Kalla Cabang Parepare dalam aktivitas operasionalnya menggunakan 27-unit komputer untuk karyawan dan 1-unit komputer server dengan penjelasan sebagai berikut:

Tabel 3. Jumlah Komputer Perusahaan

\begin{tabular}{|l|l|l|l|}
\hline No & \multicolumn{1}{|c|}{ Jenis Komputer } & \multicolumn{1}{|c|}{ Lokasi } & \multicolumn{1}{|c|}{ Jumlah } \\
\hline 1 & Komputer Persobal & Ruang Pelayanan Customer & 2 \\
\hline 2 & & Ruang Service & 7 \\
\hline 3 & & Gudang Suku Cadang & 2 \\
\hline 4 & & Ruang Kasir & 1 \\
\hline 5 & & Ruang Sales & 1 \\
\hline 6 & & Ruang SST & 1 \\
\hline 7 & & Ruang Staf Administrasi & 9 \\
\hline 8 & & Ruang Kepala Cabang & 1 \\
\hline 9 & & Ruang Part Sales & 3 \\
\hline 10 & Komputer Server & Ruang Server & 1 \\
\hline Total Komputer & & 28 Unit \\
\hline
\end{tabular}

Sumber: Hasil olah data, 2018

Data tabel di atas menunjukkan bahwa jumlah komputer yang ada di PT Hadji Kalla Cabang Parepare berjumlah 28 unit dimana jumlah komputer personal 27 ditambah dengan 1 komputer server. Dari 28-unit komputer, 4 diantaranya digunakan sebagai pengolah data (EDP) penjualan dan penerimaan kas yang terdiri dari masing masing divisi 1 karyawan pada bagian penjualan unit, 1 karyawan pada bagian penjualan suku cadang, 1 karyawan pada bagian servis kendaraan, dan 1 karyawan pada bagian keuangan.

\subsection{Pembahasan}

Guna memberikan keterangan bagi pemecahan masalah yang diteliti, maka penulis menggunakan metode analisis deskriptif kualitatif yaitu metode analisis data yang menggambarkan dan menginterpretasikan, serta membandingkan data-data penelitian yang diperoleh dari lokasi penelitian dengan literatur-literatur yang ada kemudian dianalisis. 
Agar dapat menjawab hipotesis yang penulis angkat dalam penelitian ini, maka penulis melakukan analisa data yang diperoleh dari hasil wawancara (interview) dan pengamatan langsung (observasi) yang dilakukan pada lokasi penelitian yaitu PT Hadji Kalla Cabang Parepare. Untuk menjawab apakah benar atau tidak jika PT Hadji Kalla Cabang Parepare menerapkan mekanisme pengolahan data secara langsung (real time processing), maka akan dijelaskan berdasarkan tabel berikut:

Tabel 4. Indikator Real Time Processing

\begin{tabular}{|c|c|c|c|}
\hline No & Indikator Real Time Processing & Hasil Analisis & Instrumen \\
\hline 1 & $\begin{array}{l}\text { Pengolahan data dilakukan dengan } \\
\text { segera atau secara langsung saat } \\
\text { selesainya transaksi }\end{array}$ & Sesuai & $\begin{array}{c}\text { Wawancara dan } \\
\text { observasi }\end{array}$ \\
\hline 2 & $\begin{array}{l}\text { Data yang diolah merupakan data } \\
\text { transaksi yang berintensitas tinggi } \\
\text { dan sifatnya rutin }\end{array}$ & Sesuai & $\begin{array}{c}\text { Wawancara dan } \\
\text { observasi }\end{array}$ \\
\hline 3 & $\begin{array}{l}\text { Dapat menampilkan informasi yang } \\
\text { dibutuhkan kapan saja sesuai } \\
\text { keperluan }\end{array}$ & Sesuai & $\begin{array}{c}\text { Wawancara dan } \\
\text { observasi }\end{array}$ \\
\hline
\end{tabular}

Sumber: Hasil olah data, 2018

Berdasarkan tabel di atas, maka dapat dijelaskan bahwa antara fakta di lokasi penelitian sesuai dengan yang tertulis pada tabel indikator, sehingga disimpulkan bahwa PT Hadji Kalla Cabang Parepare menerapkan pengolahan data secara langsung (real time processing). Mekanisme pengolahan data secara langsung (real time processing) merupakan pengolahan data yang meminimalisir jeda waktu antara transaksi dengan pengolahan data. Pengolahan dengan mekanisme real time processing tidak dilakukan secara menumpuk sehingga data dapat diolah satu persatu sesuai dengan waktu terjadinya transaksi dan dapat menampilkan informasi hasil olah data dengan cepat.

Agar dapat membuktikan bahwa apakah penerapan electronic data processing (EDP) system telah mendukung pencapaian informasi akuntansi yang akurat, maka penulis menggunakan tabel indikator komponen electronic data processing berikut: 
Tabel 5. Komponen Electronic Data Processing

\begin{tabular}{|c|l|c|c|}
\hline No & Komponen Electronic Data Processing & Hasil Analisis & Instrumen \\
\hline 1 & $\begin{array}{l}\text { Perangkat Keras (hardware) yang } \\
\text { memadai }\end{array}$ & $\begin{array}{l}\text { Wawancara dan } \\
\text { observasi }\end{array}$ \\
\hline 3 & Perangkat Lunak (software) yang & Sesuai & $\begin{array}{c}\text { Wawancara dan } \\
\text { observasi }\end{array}$ \\
\hline 4 & Prosedur yang memadai & Sesuai & $\begin{array}{c}\text { Wawancara dan } \\
\text { observasi }\end{array}$ \\
\hline 5 & Jaringan Komputer yang memadai & Sesuai & $\begin{array}{c}\text { Wawancara dan } \\
\text { observasi }\end{array}$ \\
\hline
\end{tabular}

Sumber: Hasil olah data, 2018

Berdasarkan hasil dari tabel di atas, maka dapat disimpulkan bahwa penerapan electronic data processing (EDP) pada PT Hadji Kalla Cabang Parepare telah mendukung pencapaian informasi akuntansi yang akurat yang dapat dilihat dari komponen EDP yang telah memadai.

\section{Simpulan dan Saran}

Kesimpulan terkait dengan penelitian ini yang dapat diuraikan bahwa dalam penerapan electronic data processing (edp) system, pihak PT Hadji Kalla Parepare menggunakan mekanisme pengolahan data secara langsung (real time processing) dimana pengolahan data tersebut dilakukan secara langsung tanpa adanya aktivitas penumpukan data. Komponenkomponen electronic data processing (EDP) system yang terdiri dari hardware, software, brainware, prosedur, serta jaringan komputer yang digunakan PT Hadji Kalla Cabang Parepare telah memadai sehingga telah medukung pencapaian informasi akuntansi yang memadai.

Adapun saran dari hasil penelitian ini adalah sebaiknya pihak perusahaan menggunakan alat pendukung berupa media penyimpanan luar data (secondary storage), agar tersedia data cadangan jika sewaktu-waktu komputer mengalami masalah; sebaiknya pemanfaatan komputer betul-betul dioptimalkan, agar manfaat yang diperoleh terkait dengan pengolahan data berbasis elektronik sebanding dengan biaya yang dikeluarkan; dan pihak perusahaan perlu untuk mempelajari cara back up data. Hal ini perlu untuk dilakukan, agar data yang mengalami gangguan atau kerusakan dapat dipulihkan dengan segera. 


\section{Daftar Pustaka}

Asiana, E. 2006. Peranan Pengolahan Data Elektronik Terhadap Sistem Pengendalian Internal Piutang (studi kasus pada PT PLN Persero Unit Bisnis Distribusi Bandung. Skripsi Fakulttas Ekonomi, Jurusan Akuntansi, Universitas Widyatama, Bandung.

Bodnar, H. George, dan W.S. Hopwod. 2006. Sistem Informasi Akuntansi, Edisi Kesembilan. Yogyakarta: Andi.

Diana, A dan L. Setiawati. 2014. Sistem Informasi Akuntansi, Perancangan, Proses dan Penerapan, Edisi 1. Yogyakarta: Andi.

Hall, J. 2009. Sistem Informasi Akuntansi. Jakarta: Salemba Empat.

Hartono, B. 2013. Sistem Informasi Manajemen Berbasis Komputer, Edisi 1. Jakarta: Rineka Cipta.

http://en.wikipedia.org/wiki/Electronic_data_processing. Diakses tanggal 20 Maret 2015.

http://kuliah.imadewira.com/pengolahan-data-elektronik. Diakses tanggal 8 Desember 2014.

http://www.irmi.com/online/inglossary/terms/e/electronic-data-processing-edp-coverage.aspx. Diakses tanggal 20 Maret 2015.

https://www.google.com/\#q=teknik+analisis +data + deskriptif + kualitatif + menurut + sugiyono \&revid=1185663778. Diakses tanggal 20 Desember 2014.

IAI. 2012. Pernyataan Standar Akuntansi Keuangan. Jakarta: Salemba Empat.

Ismail, D. 2005. Manfaat Pengolahan Data Elektronik (PDE) Penjualan Atas Pengendalian Penjualan (studi kasus pada PT Ultrajaya Milk Industry \& Trade Company, Tbk). Skripsi Fakultas Ekonomi, Jurusan Akuntansi, Universitas Widyatama, Bandung.

James, A.., George, dan Marakas. 2014. Sistem Informasi Manajemen, Edisi 9. Jakarta: Salemba Empat.

Jugiyanto. 2005. Analisis Desain dan Sistem Informasi, Edisi 3. Yogyakarta: Andi.

Jugiyanto. 2008. Sistem Teknologi Informasi, Edisi 3. Yogyakarta: Andi.

Kadir, A. 2014. Pengenalan Sistem Informasi, Edisi Revisi. Yogyakarta: Andi.

Mardi. 2014. Sistem Informasi Akuntansi, Edisi 2. Bogor: Ghalia Indonesia.

Romney, B, Marshall, dan P. John. 2014 Sistem Informasi Akuntansi, Edisi 13. Jakarta: Salemba Empat. 
Skousen dan, S. Albrecht. 2001. Akuntansi Keuangan, Edisi 1. Jakarta: Salemba Empat.

Waromantouw, K. 2005. Analisis Efektifitas Penerapan Komputerisasi Sistem Persediaan dengan Aplikasi Builder Distribution Solution (studi kasus pada PT Indonesia Permai Ria Printing Enterprise, Semarang). Skripsi Fakultas Ekonomi, Jurusan Akuntansi, Universitas Katolik Soegijapranata, Semarang. 